\title{
The Improvement of CRM in Social Networking: A Case Study of Alibaba \& Sina
}

\author{
Yang Zhao ${ }^{1,2, a}$ Lin Wang ${ }^{1,2, b}$ Nan Gao $^{1, c}$ \\ ${ }^{1}$ School of Business and Management, Northeastern University, Shenyang 110819, China; \\ ${ }^{2}$ School of Economic and Trade, Northeastern University at Qinhuangdao, Qinhuangdao 066004, \\ China. \\ aglossacherry@163.com, bwanglin05vip@163.com, 'cgaonanneuq@163.com
}

Keywords: Social customer relationship management (SCRM), Model, Social platform

\begin{abstract}
Combined with the Alibaba stake in Sina micro-blog this event, the current study elaborates upon social customer relationship management (SCRM) by analyzing from both sides of joint cause, combined action, prospect etc.,modified and organized SCRM model, put forward seven proposals for action of SCRM model. SCRM provides a new theoretical basis for research and practice.
\end{abstract}

\section{Introduction}

SCRM is a social customer relationship management system, which is an innovative concept in the field of current electronic commerce. SCRM take the customer as the center and help enterprises to better access and preservation of customer information analysis of customer behavior and to assist enterprises to make decision through the social networking platform and customer interaction. With the wave arrival of social business, SCRM is an inevitable trend. The traditional model has been difficult to apply to the SCRM, enterprises must be aware of this situation, and combined with the characteristics to take action, make timely adjustment of the existing SCRM model, at the same time to realize that the development trend of SCRM can force the business competition.

\section{Case Study on Social Customer Relationship Management Model}

Case Description. One of China's four major portal Sina (NASDAQ:SINA) is a service in China and the global Chinese community Internet media company. Sina through digital media network composed of the portal website sina, mobile portal sina and social networking and microblogging service, help customers through the Internet and mobile equipment to obtain the professional media and user generated (UGC) and interest to share with friends. Alibaba group, a diversified Internet business, is committed to creating a convenient trading channel for all the people in the world.Since its establishment, Alibaba group has established the leading consumer e-commerce, online payment, B2B online trading market and cloud computing service ${ }^{[1]}$. The evening of April 29, 2013, Sina announced that Alibaba paid \$586 million for Sina microblogging issued preferred stock, accounting for about $18 \%$ of the total shares of the microblog ${ }^{[2]}$.

\section{Case Analysis and Discovery}

\section{Alibaba commercial dilemma.}

With social business tide striking, utilization rate and penetration rate of the domestic community BBS increases year by year. In these communities and BBS, the user viscosity is high, the scale is big, user group is clear distinction, communication between the users and mutual trust is higher ${ }^{[3]}$.

User characteristics above community and forum is the demand of electronic commerce. First social carrying e-commerce can save users' time cost in selection on the e-commerce platform and the purchase of goods. Second, precision marketing for merchants increases the marketing effect and save the cost of marketing and sales. Again, trading platform focused on the community, high 
viscosity and high credibility of the communities of users will increase transaction success rate and improve the speed of transactions.

Alibaba knows that social platform boom will cause great influence on small traffic and user behavior, existing resources will be difficult to deal with more and more sellers flow import demand, On the other hand, for the sake of enhancing customer viscosity, taobao internal first started social electricity try.

Alibaba e-commerce platform in the future three goals: platform, finance and data.Micro letter are flawed, mushroom street and beautiful said "de-taobao" have effect with the three major goals of Alibaba, determining how to follow the tide of social business, to achieve three major goals, at the same time against tencent micro letter, which Alibaba is bound to think of.

\section{Sina micro-blog dilemma.}

Sina micro-blog has been the existence of commercialization dilemma. Although the emphasis has been on the "increase the number of users and the user experience, as early as 2011 weibo has technically prepare for micro-blog commercial -- the establishment of user information classification system. Sina micro-blog current profit model is mainly as follows: the official advertising, integrated implant advertising (micro study, micro radio,micro film, micro Journal), the value-added service type (member, micro-blog business school, micro interview, application square).At the end of 2013, weibo number registered users of Sina micro-blog has been close to 530 million. But on the other hand, determining how will 530 million users promoted to potential users, Sina micro-blog also face many problems: (1) Sina micro-blog official fee model stiff, low utilization rate of paid services.(2) marketing account increases, garbage micro-blog increases. (3) The user active degree decline. Micro message friends active degree rise,"V" event bad influence on Sina micro-blog. (4) The loss of a large number of new user,new user fatigue,the number of Sina micro-blog registered users has already peaked. (5) From the micro letter competition pressure. At the beginning of the end of 2012, the industry turn to the promising micro letter.In the long run, the micro letter coverage for the users of life is more and more high. For Sina micro-blog, the essence of the competition with Tencent micro letter is to see who can grab more and cover the user's entire life.

\section{Combined with the inevitable.}

Sina micro-blog has " social network" and "media platform" dual attributes,which fully meet the Alibaba social business needs. the opposite relationship between Sina and micro-blog has already formed, the opposite relationship between Alibaba and Tencent has also already formed, combined with both advantages against common competitor is a win-win choice. Sina Weibo huge user groups bring difficult to measure information and a large amount of data. These data and information resource value can realize precise advertising, and dig more user behavior and user demand. Taking a stake in sina weibo for alibaba platform and data two goals is very good.According to Alibaba "data exchange agreement with Sina, sina weibo's 530 million registered users of Sina weibo" footprint ", can be for big data analysis of Alibaba, analysis of behind can produce a large number of commercial value, it can not be denied.

The profit model of sina is in trouble, by introducing alibaba investment share offering, secure advertising orders worth $\$ 380$ million at the same time through social e-commerce of tmall alipay, which exchange of data, increase user groups and try more conducive to long-term camp confrontation with tencent micro letter.

\section{Combined actions.}

Both sides account communication, data communication: Alibaba and Sina has the massive and high quality of users and data, but the integration of these data is not easy. Data integration involves a lot of problems, the two sides established a joint team docking data, and exchange of permanent staff. Privacy of users cann't be ignored in the process of data integration. All of user microblog information can't be connected with taobao,and all of the browsing and shopping data of taobao users can't be simply connected in micro blog. Both platforms such as microblog, taobao set account interworking buttons, good setting is that the user can choose whether or not to account bound 
according to their own wishes . In addition based on data mining, Alibaba and Sina mainly study. Comparative analysis of one group shopping behavior and microblog content.

Micro-blog payment: In January 2014, Sina micro-blog and Alibaba jointly launched micro-blog payment through Sina micro-blog and Alibaba's Alipay account. Microblog pay only three steps: find the related merchandise in the microblog; Binding Alipay account, input Alipay or Taobao account name and password; enter the payment password to complete payment. Through this partnership, the two sides will further strengthen the microblogging " browse - interest - order payment - sharing " social marketing closed-loop advantage.

\section{Analysis and verification of the model.}

Sina micro-blog and Alibaba cooperation is the biggest social customer relationship management in domestic practice, is also the biggest implementation platform of social customer relationship management.

Alibaba group itself and tmall Taobao countless shops are through the platform of sina micro-blog on social customer relationship management (SCRM).The push of social software in Ali dealings, The push of social software in Laiwang dealings, Ma Yun had to send mail to express Ali determination. Ali internal staff must use Laiwang dealings and external friends (non Ali staff) number must be greater than 100 , otherwise, there is no annual bonus ${ }^{[4]}$.

It is not difficult to see that the promotion of enterprise social customer relationship is inseparable from the internal staff or recommend people, enterprise or small businesses release and share information through microblog platform.Taobao a main fashion women as an example, Sina build their own micro blog to release information, at the same time in Taobao shop placed advertising content "focus on micro, i.e. to reduce 5 yuan" to establish micro blog entry, where you focus on microblog and screenshots each shopping to customer service can subtract 5 yuan in cash.

His microblog mainly display products and shooting sidelights. through the interaction with the ruili model, the shop microblog accumulated the first group of fans, "focus on microblog, that is, subtract 5 yuan" activities for accumulating the second batch of fans. At the same time micro blog released a promotional information from time to time, then draw award quota in the fan, vouchers, in order to improve the viscosity of fans. Forwarding @ three friends for lucky draw at the same time, improve microblog visibility to improve viscosity at the same time increase the number of fans. .Above actions based on enterprise internal employees or middlemen establish influence for news and promotion on the platform. Such as model (1):

The micro-blog responsible person every day try to reply to customer @ his content. It is part of the after-sales service. At the same time, through information collection, he can know customer's idea as soon as possible, make fashion strategy adjustment timely for some small PR crisis management. There was a buyer on Sina Weibo @ their shop, send the wrong product description. So he gave the customer apologized and promised to remedy immediately afterwards the buyer on the microblogging praised the customer service. This is a process of small shops, involving relatively simple, focused microblogging marketing and after-sales service. The process for the formation of customer knowledge is no significant outstanding. Group shopping behavior analysis based on data mining is an important embodiment of customer knowledge. Analysis in combination with Alibaba and Sina data will affect the generation of key customer knowledge of social business.

Fig. One shows that the model (1) for a variety of external social behaviors of enterprise customers in a social environment. (2) for social platform, enterprises in the social platform to establish social dashboard to monitor search and interact with customers. (3) for the enterprise, front-end to reach closer ties with customers through social platforms. Among various departments for better coordination, forming a back-end data processing and analysis of customer knowledge to support decision-making for individual departments. (1)(2)(3) a tight closed loop. Combined with the previous analysis, it is not difficult to see that the formation of enterprise social customer relationship management closed loop, enterprise behavior development must ultimately result feedback back to the enterprise, in view of this, the adjustment model is shown in Fig.1. 


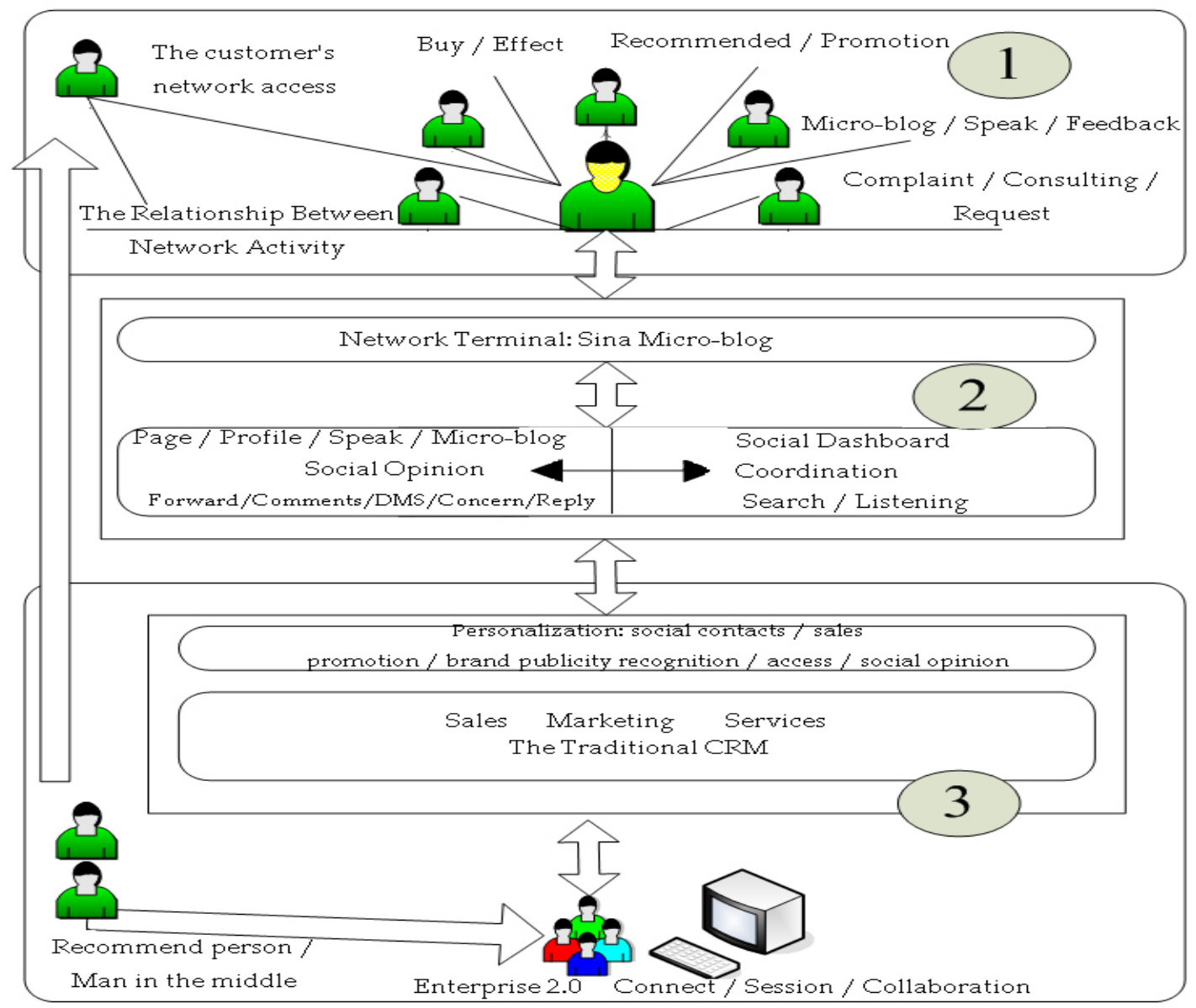

Fig. 1 The adjustment model

\section{Recommendations and actions based on the social customer relationship management model}

Enterprises need to carefully consider how to create an own brand unique social media experience, for the enterprise itself, to provide value for customers, and the use of the strong ability of social media to operating its own brand, expand its influence of social media experience. Enterprises need to consider the following aspects, and lays the foundation for the successful launch the social media plan of customer relationship.

To realize the power of social media.

For many companies, social media will become the main communication channel with customers contact.

\section{A clear distinction between social media and other channels.}

The purpose of social CRM is to achieve customer participation, so as to achieve a win-win customers and enterprises. The traditional pattern of customer relationship management from enterprises to customers need to adapt to the reality.

To create a seamless customer experience across social media and other channels ${ }^{[5]}$.

Enterprise customers in a channel, is that whether he also in other channels, whether he has produced valuable data and information in the other channel. This suggests that social solutions are not isolated plan, but the need for multi channel integration.

\section{To start from the customer point of view.}

Where is the customer is that where enterprise should be . Whether the enterprise need to be involved in social media depends on whether the customer participate in social media. Customers choosing to interact with the enterprise in the social platform must be a reason for that.Changing corporate social strategy pay attention to the customer perspective of what value is the enterprise can give needed ,so that customers can keep close with the enterprise. 


\section{Not sure what is customer value, then ask the customer in the form of interaction.}

Interaction is one of the function and form of social media. Enterprise can attract customers to participate in through the way of design innovation, such as by voting, inspire ideas and ask questions and get customer opinion of the enterprise.This behavior will help enterprises to establish support

degrees and brand viscosity.

\section{To make full use of big data.}

Social networks all the time undergoing user evaluation of the enterprise, emotional expression, the expression of user demand. Big Data era, we should take full advantage of existing upcoming social tools and data mining tools for analyzing user behavior, the formation of customer knowledge so that enterprises deeper understand customers, make strategic layout and plan the next action.

\section{To benefit from social media.}

By social media, customers could experience interacting directly with the enterprise quickly and easily. In the development of social business activities, the use of time and other factors such as sensitive promotions or discounts to stimulate specific customer groups to take action. At the same time, as a reward to provide to the customers who share content with friends, so as to realize the product or service information on the social platform of viral spread, to achieve the effect of viral marketing.

\section{Conclusions}

Combined with the times background ,this paper presents a social customer relationship management model background and get the final model, put forward seven proposals for action. Future research will be based on the social development trend of the customer relationship management (CRM), combined with changing times to adjust and improve the model.

\section{Acknowledgements}

This research is supported by funding of China's central university basic scientific research expenses Project No. N120323005.

This research is supported by funding of China's ministry of education humanities and social science youth. Project No. 13YJCZH180.

\section{References}

[1] Y.Y. Jin,Explore the new development direction of the Internet in the large data pattern enterprises -- Based on the Alibaba group and Tencent Holdings Ltd as an example, J. Theory of Urban Construction. (2014) 11. (In Chinese)

[2] F.H. Yu, Industry view: Ali Sina microblogging marriage intended to "data", J. Chinese Media Technology. 2013, pp.1. (In Chinese)

[3] K.Zhou, Discussion on the community e-commerce business model, J. Electronic commerce. 2011, pp.14-15. (In Chinese)

[4]Y. Hu, Mobile IM "War Within Three Kingdoms": free flow of ease credit stab to Micro message, J. IT time weekly. 2013, pp.36-37. (In Chinese)

[5] B.X.Zhang, Integration of e-commerce and social media, J. World of entrepreneurs. 2013, pp.32. (In Chinese) 